\title{
Laser hemorrhoidoplasty versus open hemorrhoidectomy in Upper Egypt
}

\author{
Ahmed M Hassan, ${ }^{1}$ MD, Gamal Galal Shemy ${ }^{1}$, MD.
}

* Corresponding Author:

Ahmed M Hassan

ahmedmohamedhassanahmed.44 @azhar.edu.eg

\section{Received for publication February 8, 2021; Accepted March 18, 2021; Published online March 18, 2021.}

Copyright 2020 The Authors published by Al-Azhar University, Faculty of Medicine, Cairo, Egypt. All rights reserved. This an open-access article distributed under the legal terms, where it is permissible to download and share the work provided it is properly cited. The work cannot be changed in any way or used commercially.

doi: 10.21608/aimj.2021.57763.1397.

${ }^{1}$ General Surgery Department, Faculty of Medicine (Assuit), AlAzhar University, Egypt.

\begin{abstract}
Background: Using a Hemorrhoid laser procedure (LHP) in this Comparative study was proved to be more effective, easily used, noninvasive, non-toxic, painless, and highly effective. Hemorrhoid laser procedure (LHP) is a recent maneuver for the management of hemorrhoids (piles) wherein the rectal arterial flow supplying the hemorrhoidal plexus is closed by laser coagulation.

Aim of the study: to asses the comparison of safety, efficacy and advantages of LHP with the open technique for the treatment of patients complained from hemorrhoids.

Patients and Methods: This study was done at the department of general surgery, Al-Azher Al-Al university Hospital, Assuit, and Al-Rehab Hospital, Assuit between November 2019 and November 2020. 40 Patients complained for grade III hemorrhoids were combatable for this study. Those patients had been divided into 2 groups. Group I: Twenty patients managed by the LHP, and Group II: Twenty patients managed with open hemorrhoidectomy. Evaluation of the time of the operation, postoperative bleeding and pain with a visual analog scale, was done.

Results: The number of male patients was 23 and female patients were 17 . There were major considerable variations in regard of operative time, postoperative bleeding and early postoperative pain between laser hemorhoidoplasty and open surgical technique. There were statistically considerable differences among the 2 groups concerning the early postoperative period $(\mathrm{p}<0.01)$. The Average operative time for LHP was 15.90 minutes versus 26.80 minutes for the open technique $(\mathrm{p}<0.01)$.

Conclusion: LHP had greater effectiveness than the open approach concerning Postoperative pain, bleeding and operative time.
\end{abstract}

Keywords: Laser hemorhoidoplasty; open hemorrhoidectomy; bleeding; pain...

Disclosure: The authors have no financial interest to declare in relation to the content of this article. The Article Processing Charge was paid for by the authors.

Authorship: All authors have a substantial contribution to the article.

\section{INTRODUCTION}

Hemorrhoids are a common anorectal problem. Patients suffered from hemorrhoidal disease may complain of a variety of symptoms, but there are two cardinal symptoms bleeding and prolapse. The principles of treatment for hemorrhoids are to alleviate symptoms, not necessarily to improve the appearance of the anal canal. ${ }^{1}$ The estimated worldwide prevalence of Hemorrhoidal disease ranges from $2.9 \%$ to $27.9 \%$, more than $4 \%$ of which are symptomatic. ${ }^{1,2}$ Nearly, 1/3 (33.3\%) of those patients search for medical consultation. Race distribution showing that a Gaussian distribution with a top prevalence among 40 and 65 years followed by the decrease of the prevalence after the age of $65 .{ }^{3,4}$ Female patients are less frequently affected than male. ${ }^{5}$ The anorectal vascular cushions in conjunction with the sphincter ani internus (IAS) are important in the preservation of continence through providing soft tissue support and maintaining tight closure of the anal canal. Taken into consideration Hemorrhoids are due to the downward displacement of suspensory (Treitz) muscle. ${ }^{6}$ Patients with hemorrhoidal disorder can also additionally complained of a variety of symptoms, but there are two cardinal symptoms bleeding and prolapse. ${ }^{7}$

Patients with asymptomatic hemorrhoids do not need management. Treatment varies from simple measures which include dietary modification, alternate defecatory habits to office maneuvers and operative hemorrhoidectomy.

In symptomatic patients with third and fourth-degree piles the ideal treatment is Hemorrhoidectomy. Despite hemorrhoidectomy is considered as a minor approach, it is also related to considerable 
postoperative drastic effects, which include severe pain, bleeding, long operative time and infected wound that led to prolongation of the period of recovery. ${ }^{8}$

Recent advances in devices which include laser hemorhoidoplasty have been considered an effective alternative, with reduction of pain, reduction of blood loss, accelerate healing of the wound and faster return to ordinary activities. The management modalities for symptomatic patients with hemorrhoids have varied over time. These alternatives modalities have included conservative medical control, non-surgical management and numerous surgical approaches. The various non-surgical procedures consist of rubber band ligation (RBL), injection sclerotherapy, cryotherapy, infrared coagulation. All of which can be achieved as outpatient approaches without anesthesia. These non-surgical procedures are considered to be the primary choice for grades I to III hemorrhoids. ${ }^{8}$ in the failure of conservative approaches to control symptoms, the strategy of treatments was changed to surgical treatments. The indicators to shift for surgery consist of the presence of a considerable external component, hypertrophied papillae, thrombosed piles or recurrence of previous presentations. The surgical procedure was open (Milligan-Morgan) and the instruments used are the scalpel, scissor, electrocautery. Milligan-Morgan hemorrhoidectomy is the gold standard and frequently performed approach in the United Kingdom. ${ }^{9}$ Post hemorrhoidectomy pain is the most common drastic complication associated with surgical procedures. The retention of urine $(20.1 \%)$, bleeding (secondary or reactionary) $(2.4 \%-6 \%)$ and subcutaneous abscess $(0.5 \%)$ are other early complications. The delayed drastic compilations consist of anal fissure (1\% $2.6 \%$ ), anal stenosis ( $1 \%)$, incontinence $(0.4 \%)$, fistula $(0.5 \%)$ and recurrence of hemorrhoids. ${ }^{10,11}$

\section{PATIENTS AND METHODS}

\section{Preoperative assessment}

An informed written consent was taken from all patients who accepted for participation in the study. A full history was taken, physical examination, per rectal examination and proctoscopy. Routine preoperative investigations which were performed include complete blood count, random blood sugar, liver function test, kidney function test, and coagulation profile. In this comparative and prospective study 40 patients were included, which were divided into 2groups, Group I: 20 patients were managed with laser hemorhoidoplasty and group II: 20 patients treated with open surgical hemorrhoidectomy. This study was performed at the department of general surgery, AlAzher University Hospital, Assuit, Al-Rehab Hospital, Assuit between November 2019 and November 2020. After a detailed physical examination and proctoscopy, the laser technique was performed with (Biolitec AG, Germany) (Figure1).

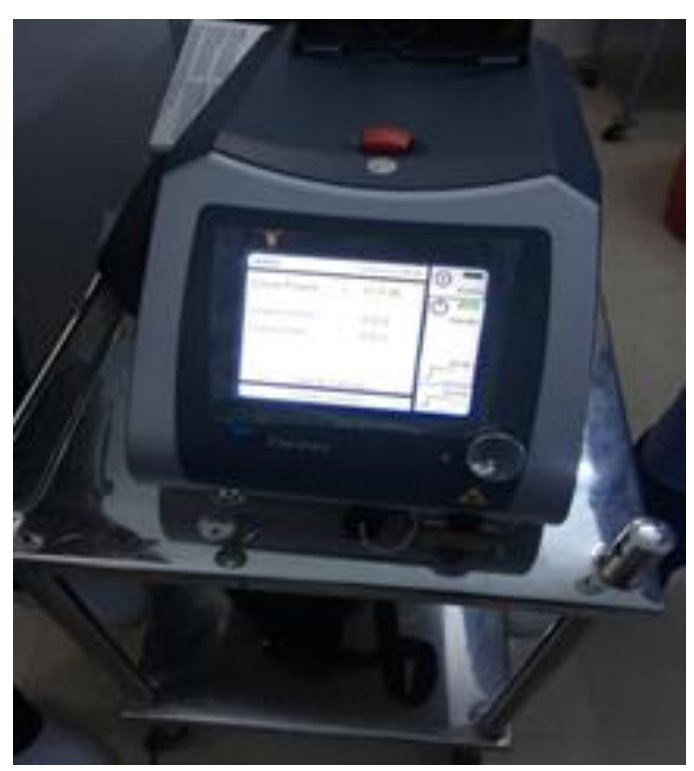

Fig 1: Biolitec AG, Germany.

\section{Operative technique}

Group I: The position of the patient is the lithotomy, lubricated proctoscope was introduced into the anus (Fig. 2). This approach has been started via a small incision at the mucocutaneous junction. the laser fiber was introduced into the hemorrhoidal plexus taking into consideration that the fiber should be parallel to the anal canal to avoid injury or burn of the mucosa or internal sphincter (Fig. 3). Using a $1470 \mathrm{~nm}$ diode laser, laser shots were delivered through the optic fiber in a pulsed fashion for the reduction of favorable degeneration of the periarterial healthy tissue. The limits of shrinkage can be controlled by the duration and power of the laser beam. Via the optic fiber, laser shots were generated at a power of $8 \mathrm{~W}$ with the duration of $7 \mathrm{~s}$ each shot followed by a pause of $1 \mathrm{~s}$ caused shrinkage of tissues approximately up to the depth $5 \mathrm{~mm}$. at the end of each hemorrhoid, an ice finger was applied intra anally for 1-2 minutes to minimize the harmful effect of heat (Fig. 4). This procedure was repeated for each hemorrhoid.
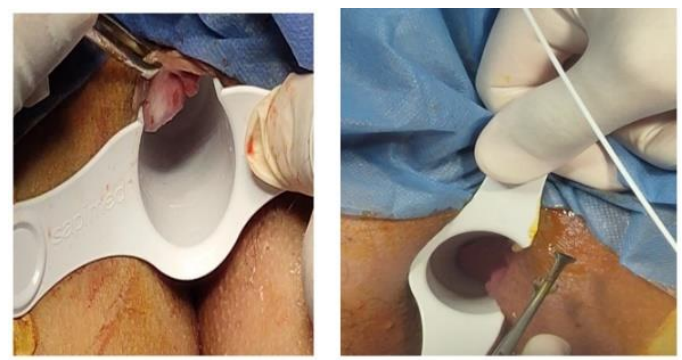

Fig 2: Introduction disposable proctoscope. 

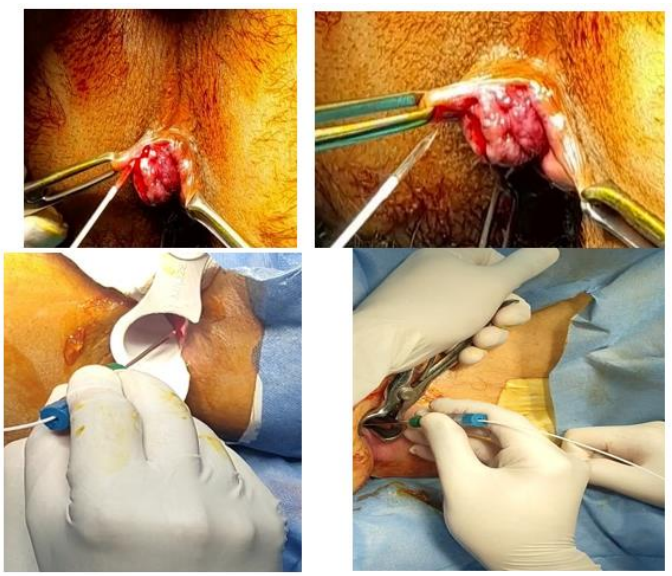

Fig 3: Introduction of probe at mucocutaneous junction.
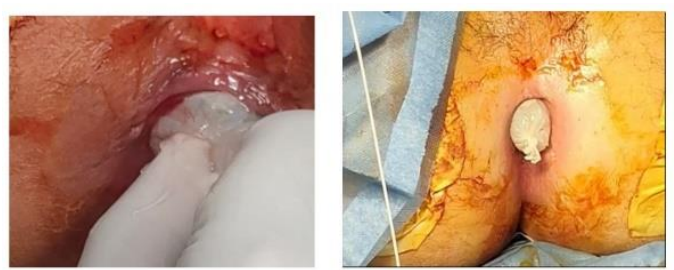

Fig 4: Introduction disposable proctoscope.

The discharged time of the Patients ranged from four to twelve hours, and the period of follow-up ranged from 2 to 6 months for evaluation of the progress of healing and complications. This approach was done as an outpatient maneuver. Preparation of bowel wasn't needed.

Group II: 20 patients were treated with open surgical hemorrhoidectomy under spinal anesthesia. after gentle dilatation of anus, hemorrhoid is held by artery forceps one at pedicle and other at mucocutaneus junction, then V-shaped incision in the skin is made (Fig. 6) and deepened to pedicle down to underlying sphincter then pedicle is transfixed and ligated (Fig. 7) and the pile is excised 112 inch distal to ligature leaving the wound open. 2 to 3 hemorrhoids may be treated in the same manner. Patients were discharged within 4 to 12 hours and were followed for 2 to 6 months for healing progress and complications. Follow up of the patients for the level of postoperative pain and duration of the operation. Postoperative pain was recorded by using a 10-point visual analog scale (VAS) on which 0 represents no pain and 10 represents the worst pain imaginable. VAS protocol was followed up after 1 week, 2 weeks, 3 weeks, 1 month, 2 months and 6 months. The duration of intervention was recorded in minutes. The data were analyzed with statistical tests and presented with respective tables.

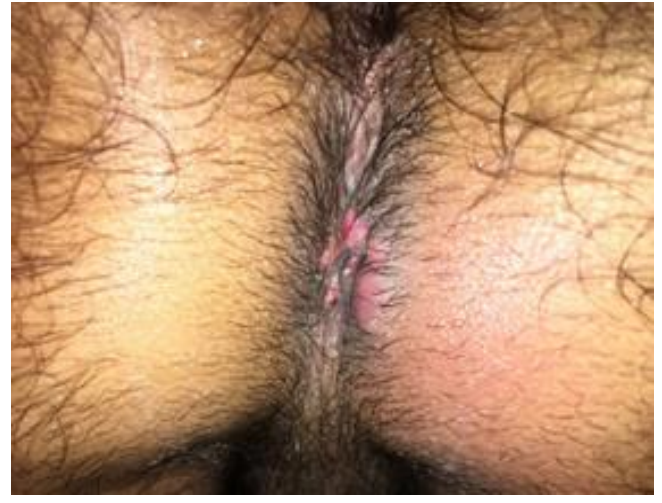

Fig 5: Post LHP abscess formation.

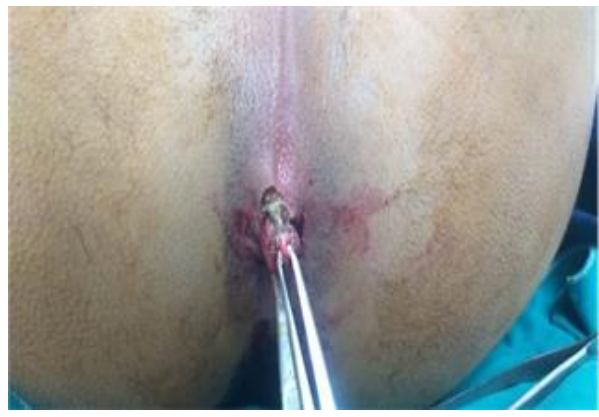

Fig 6: V shaped incision in skin at mucocutaneous junction.

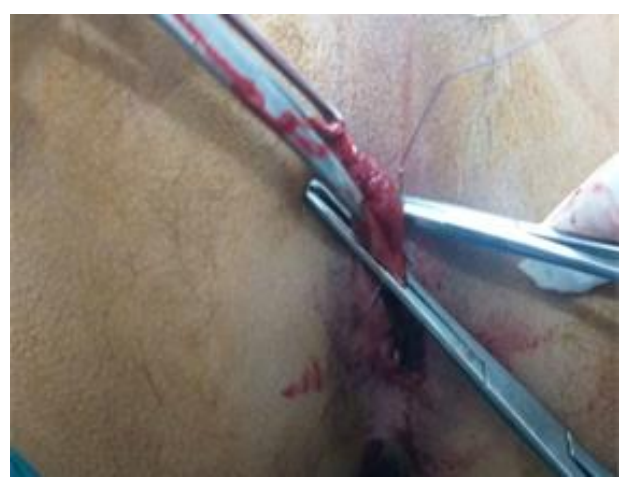

Fig 7:Pedicle is transfixed and ligated.

\section{RESULTS}

The LHP was done on 20 consecutive patients which had symptomatic third-degree piles associated with mild prolapsed mucosa at proctoscopic examination and a history of infrequent attacks of prolapse which reduced manually, with mean age $47 \pm 12.6$ (range, 24-70) years. The number of male patients was 12 and 8 females. (Table1). The open surgical procedure was performed on 20 patients which had symptomatic grade III hemorrhoids and with or without complete prolapse. With mean age $49 \pm 12.3$ (range 28-72) years. The number of male patients was 11 and 9 females (Table 1). 


\begin{tabular}{|l|l|l|}
\hline & $\begin{array}{l}\text { No. }(\%) \text { or } \\
\text { Mean } \pm \text { SD }\end{array}$ & $\begin{array}{l}\text { No. }(\%) \text { or } \\
\text { Mean } \pm \text { SD }\end{array}$ \\
\hline Age (years) & Group I & Group II \\
\hline & $\begin{array}{l}47 \pm 12.6 \\
(24-70)\end{array}$ & $\begin{array}{l}49 \pm 12.3 \\
(28-72)\end{array}$ \\
\hline $20-29$ & $2(10.0 \%)$ & $3(15.0 \%)$ \\
\hline $30-39$ & $7(35.0 \%)$ & $5(25.0 \%)$ \\
\hline $40-49$ & $5(25.0 \%)$ & $6(30.0 \%)$ \\
\hline $50-59$ & $4(20.0 \%)$ & $4(20.0 \%)$ \\
\hline $60-70$ & $2(10.0 \%)$ & $2(10.0 \%)$ \\
\hline Sex & & \\
\hline Men & $12(60.0 \%)$ & $11(55.0 \%)$ \\
\hline Women & $8(40.0 \%)$ & $9(45.0 \%)$ \\
\hline
\end{tabular}

Table 1: Characteristics of the patient group.

While the average time of hospitalization ranged from 4 to 12 hours in Group I, and ranged from 12 to 18 hours, with a mean of $13.8( \pm 2.82)$ hours in Group II (Table 2). The mean operative time was $15.90 \pm 3.5$ $\mathrm{min}$ in the LHP group and $26.80 \pm 5.8 \mathrm{~min}(\mathrm{p}<0.01)$ (Table 3 ). As regard pain, early postoperative pain is lower in group I than group II. The same values also resulted for one month. These results are presented in Tables 4,5. No major drastic effects or complications were reported except 1 case recurrence and 1case stricture due to excess mucosal removal in Group II. Bleeding was observed in one case (the patient was taking aspirin) in Group I. And 2cases in Group II. One of the 2 patients was reported for surgical hemostasis which was necessary. Mild pain that necessitates medical treatment was recorded in 3 patients, one in LHP group and two in open surgery.
No blood transfusions were needed in any of the cases. As regard to post-operative oedema there was one case reported in LHP group and three cases were reported in the open hemorrhoidectomy group. Also, there wasone case complained from post LHP abscess formation. (Fig. 5).

\begin{tabular}{|l|l|l|}
\hline & Group I & Group II \\
\hline $\begin{array}{l}\text { Operative time } \\
\text { (minutes) }\end{array}$ & $\begin{array}{l}15.90 \quad \pm 3.5 \\
\min \end{array}$ & $\begin{array}{l}26.80 \quad \pm \quad 5.8 \\
\min \end{array}$ \\
\hline Hospital stays & $(4-12)$ & $\begin{array}{l}13.8 \pm 2.82(12 \\
-18)\end{array}$ \\
\hline
\end{tabular}

Table 2: Operative time and hospital stay.

\begin{tabular}{|l|l|l|}
\hline $\begin{array}{l}\text { Early postoperative } \\
\text { complications }\end{array}$ & Group I & Group II \\
\hline Pain & $1(5.0 \%)$ & $2(10.0 \%)$ \\
\hline Abscess & $1(5.0 \%)$ & $0(0.0 \%)$ \\
\hline Bleeding & $1(5.0 \%)$ & $0(0.0 \%)$ \\
\hline Edema postoperative & $1(5.0 \%)$ & $3(15.0 \%)$ \\
\hline $\begin{array}{l}\text { Late } \\
\text { complications }\end{array}$ & \\
\hline Fistula within 6 & 0 & 0 \\
\hline Stricture & 0 & 1 \\
\hline $\begin{array}{l}\text { Recurrence } \\
\text { months }\end{array}$ & 0 & 0 \\
\hline Incontinence & 0 & 1 \\
\hline
\end{tabular}

Table 3: Operative and Early Postoperative complications in both groups.

\begin{tabular}{|l|l|l|l|l|l|l|l|}
\hline $\begin{array}{l}\text { VAS } \\
\text { score }\end{array}$ & Day 1 & Day 7 & Day 14 & Day 21 & Month 1 & Month 2 & Month 6 \\
\hline $0-1$ & $5 / 20$ & $19 / 20$ & $19 / 20$ & $20 / 20$ & $20 / 20$ & $20 / 20$ & $20 / 20$ \\
\hline $2-5$ & $15 / 20$ & $1 / 20$ & $1 / 20$ & $0 / 20$ & $0 / 20$ & $0 / 20$ & $0 / 20$ \\
\hline$>5$ & $0 / 20$ & $0 / 20$ & $0 / 20$ & $0 / 20$ & $0 / 20$ & $0 / 20$ & $0 / 20$ \\
\hline
\end{tabular}

Table 4 Pain presentation by VAS score in the LHP group

\begin{tabular}{|l|l|l|l|l|l|l|l|}
\hline $\begin{array}{l}\text { VAS } \\
\text { score }\end{array}$ & Day 1 & Day 7 & Day 14 & Day 21 & Month 1 & Month2 & Month 6 \\
\hline $0-1$ & $0 / 20$ & $0 / 20$ & $8 / 20$ & $15 / 20$ & $18 / 20$ & $20 / 20$ & $20 / 20$ \\
\hline $2-5$ & $18 / 20$ & $20 / 20$ & $12 / 20$ & $5 / 20$ & $2 / 20$ & $0 / 20$ & $0 / 20$ \\
\hline$>5$ & $2 / 20$ & $0 / 20$ & $0 / 20$ & $0 / 20$ & $0 / 20$ & $0 / 20$ & $0 / 20$ \\
\hline
\end{tabular}

Table 5: Pain presentation by VAS score in the surgical group

\section{DISCUSSION}

Laser Hemorhoidoplasty has been available as a new modality of minimally-invasive procedure alternative treatment of advanced hemorrhoid problems. ${ }^{12}$ This technique is newly practiced in upper Egypt. For the satisfaction of our knowledge, few studies ${ }^{13}$ have discussed this area of research involving laser hemorhoidoplasty for management of third- or fourthdegree piles.
The need for management for hemorrhoids is primarily based on the subjective perception of the severity of presentations and the challenge of management is determined on the conventional degree of hemorrhoids, ${ }^{14}$ which is not related to the severity of symptoms. Variations of management approaches have delivered confusion in the decision about the effective management modalities. So that the optimum management modalities remain unanswered despite most of the procedures in use being subjected to randomized assessment. Generally, an 
uncomplicated hemorrhoidectomy is satisfactory on non-surgery or operation for both, patient and surgeon (15). Salfi 2009, and Chia et al. 1995 said that LHP had the benefits of being bactericidal, better hemostasis, rapid recovery, with no harmful effect to surrounding tissues, much less postoperative complications and less bleeding and stenosis. ${ }^{16,17}$

Open hemorrhoidectomy is the most widely accepted technique in the treatment of symptomatic patients with hemorrhoids. However, open hemorrhoidectomy is related to considerable complications which include postoperative pain, blood loss and wound sepsis that may lead to prolongation of hospitalization. ${ }^{18}$ The pain scores at this current study were considerably low in LHP patients compared with open hemorrhoidectomy procedure group, in the early postoperative period after VAS a score was 5 versus 0 for score $0-1,15$ versus $^{19}$ for score $2-5$ and 0 versus 2 for score above 5 in the respective groups. Pain that occurs postoperatively is the most critical drastic effect that disturb the patients and make them reluctant to surgical procedures. In the current study, postoperative pain during the first month after both procedures was significantly lesser in the Laser hemorhoidoplasty compared with conventional open surgical hemorrhoidectomy $(\mathrm{p}<0.05) .{ }^{20} \mathrm{This}$ article confirmed that LHP is a secure procedure accompanied by much less postoperative pain. Also, Laser hemorhoidoplasty is accompanied with much less operative time compared with open surgical hemorrhoidectomy, which is better for symptomatic cases with third- and fourth-degree piles (15.90 vs. $26.80 \mathrm{~min}$ and $\mathrm{p}<0.01){ }^{21}$

Laser hemorhoidoplasty is a painless and minimally invasive technique for day-surgery management of piles figuring out the shrinkage of the hemorrhoid by means of a diode laser. ${ }^{22,23}$

Regard the postoperative complications in the current study, there were 2 cases complicated (10\%) in Group I and 5 (25\%) patients in Group II. In group I There was one patient had pain $(5 \%)$ and abscess (5\%), while the second case had bleeding $(5 \%)$ and edema (5\%). and in Group II there 2 cases had pain (10\%) and 3 cases had post-operative edema (15\%). And as regards to late post-operative complications as fistula, stricture, incontinence, or 6-month recurrence no recorded cases in Group I. But there were 2 recorded cases. The first one complained about stricture and the second one from 6-month recurrence. The result of Jahanshahi 2012 et al. ${ }^{(24)}$ Study reports that LHP is a safe approach for the management of hemorrhoids due to fewer postoperative complications such as bleeding, pain, stenosis, and recurrence. Different studies reported that LHP was more effective than open hemorrhoidectomy in terms of reduced postoperative pain, operative time, blood loss, and time to return to normal activity. Another study has reported the superiority of using LHP rather than open hemorrhoidectomy in patients with symptomatic hemorrhoid nonresponding to medications. This promising efficacy was practical in form of reduction of post-operative pain, bleeding, length hospitalization, and reduction of postoperative analgesia. ${ }^{25}$ The same results were recorded by others in a study was done on twenty cases managed by LHP. ${ }^{26}$ Certain precautions should be in mind during LHP, which include the fiber should be parallel to the anal canal to avoid injury or burn of the mucosa or internal sphincter, laser shots were delivered through the optic fiber in a pulsed fashion for the reduction of favorable degeneration of the periarterial healthy tissue. One of the major limitations of our study is the lack of long-term follow-up and assessment because two-year follow-up was not available for all patients. However, all patients who participate in this study are still under assessment for further evaluations in the future. Another limitation is few numbers of the patient in this study.

\section{CONCLUSION}

The safety and efficacy of LHP is more than open hemorrhoidectomy accompanied with a low incidence of post-operative complications and it is more effective in third-degree than fourth degree piles. ${ }^{27 .}$

LHP technique is superior to conventional open surgical hemorrhoidectomy. With less Postoperative pain in comparison with surgical maneuver $(p<0.05)$. Operative time is significantly shorter in laser procedure $(\mathrm{p}<0.01){ }^{28 .}$

\section{REFERENCES}

1- Johanson JF, Sonnenberg A. The prevalence of hemorrhoids and chronic constipation: an epidemiological study. Gastroenterology. 1990; 98: 380:6.

2- Rogozina VA. Hemorrhoids. Eksperimental'Naia i Klinicheskaia. Gastroenterologiia. 2002; 4: 93 6.

3- Abcarian H., Alexander-Williams J., Christiansen, J., et al. Benign anorectal disease: definition, characterization and analysis of treatment. Am. J. Gastroenterol. 1994; 89, 182- 93.

4- Parks AG. De Hemorrhoids. A study in surgical history. Guy's Hospital Report. 1955; 104: 135 50 .

5- Keighley MRB. Surgery of Anus, Rectum and Colon. 1. Vol. 1, WB Saunders publishers. 1993: 295-8.

6- Haas PA, Fox TA Jr and Haas GP. The Pathogenesis of hemorrhoids. Diseases of the colon and rectum. 1984; 27: 442-50.

7- Thomson WHF. The nature of Hemorrhoids. British Journal of Surgery. 1975; 62: 542-52.

8- MacRae HM and McLeod RS. Comparison of Hemorrhoidal Treatment Modalities. A metaanalysis. Dis Colon Rectum. 1995; 38: 687-94.

9- Monson JRT, Mortenson NJ and Hartley J. Procedures for Prolapsing Hemorrhoids (PPH) or Stapled Anopexy. Consensus Document for Association of Coloproctology of Great Britain and Ireland. ACPGBI. 2003.

10-Bleday R, Pena JP, Rothenberger DA, et al. Symptomatic Hemorrhoids: Current Incidence and Complications of Operative Therapy. Diseases of the colon and rectum. 1992; 35: 47781. 政

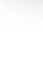


11- Sardinha TC and Corman ML. Hemorrhoids. The Surgical clinics of North America. 2002; 82: 115367

12-Weyand G, Theis CS, Fofana AN, et al. Laser hemorrhoidoplasty with $1470 \mathrm{~nm}$ diode laser in the treatment of second to Fourth degree hemorrhoidal disease - a Cohort study with 497 patients. Zentralbl Chir. 2019; 144: 355-63.

13-Brusciano L, Gambardella C, Terracciano G, et al. Postoperative discomfort and pain in the management of hemorrhoidal disease: laser hemorrhoidoplasty, a minimal invasive treatment of symptomatic hemorrhoids. Updates Surg. 2019.

14- wazli LG. Hemorrhoidectomy Using $(10600 \mathrm{~nm})$ CO2 Laser. Iraqi Journal of Laser. 2018; 13: 33 39.

15- Goligher J, Duthie H and Nixon H. Surgery of the Anus Rectum and Colon. 5. London: Baillière Tindall. 1984.

16-Salfi R. A new technique for ambulantory hemorrhoidal treatment Doppler-guided laser photocoagulation of hemorrhoidal arteries. Coloproctology. 2009; 31: 99-103.

17- Chia YW, Darzi A, Speakman CT, et al. CO2 laser hemorrhoidectomy--does it alter anorectal function or decrease pain compared to conventional hemorrhoidectomy? J Colorectal Dis. 1995; 1011: 22-24.

18-Laurie Barcly. Best option for evaluating and treating hemorrhoids. BMJ. 2008; 336: 380-3.

19- Milligan ET, Morgan CN and Jones LE. Surgical anatomy of the anal canal and the operative treatment of hemorrhoids. Lancet. 1937; 2: 1119. 24.

20-Maloku H, Gashi Z, Lazovic R, et al. Laser hemorrhoidoplasty procedure vs open surgical hemorrhoidectomy: a trial comparing 2 treatments for hemorrhoids of third and fourth degree. Acta Inform Med. 2014; 22: 365-7.

21-Naderan M, Shoar S, Nazari $M$, et al. A randomized controlled trial comparing laser intrahemorrhoidal coagulation and Milligan-Morgan hemorrhoidectomy. J Invest Surg. 2017; 30: 32531.

22-José MMB. Initial Experience of Anorectal Surgery with Laser Technique. EC Gastroenterology and Digestive System. 2020; 7 : 01-11.

23-Maloku H, LazovićR and Terziqi H. Laser hemorrhoidoplasty versus MilliganMorgan hemorrhoidectomy - short-term outcome. Vojnosanit Pregl. 2019; 76: 8-12.

24- Jahanshahi A, Mashhadizadeh E and Sarmast MH Diode laser for treatment of symptomatic hemorrhoid: a short-term clinical result of a mini-invasive treatment, and one-year follow-up. Pol Przegl Chir. 2012; 84: 329-32.

25-Sadra M and Keshavarz M. Comparison of intrahemorrhoidal coagulation with 980 nanometer diode laser and Milligan-Morgan hemorrhoidectomy. J Clin Res Gov. 2015; 4: 1-4.

26-Maloku H, Gashi Z, Lazovic R, et al. Laser hemorrhoidoplasty procedure versus open surgical hemorrhoidectomy. Acta Inform Med. 2014; 22: 365-7.

27-Eskandaros MS and Darwish AA. Comparative study between Milligan- Morgan hemorrh- oidectomy, stapled hemorrhoidopexy, and laser hemorrhoidoplasty in patients with third degree hemorrhoids: a prospective study. Egypt J Surg. 2020; 39: 352-63.

28-Alsisy AA, Alkhateep YM and Salem IE. Comparative study between intrahemorrhoidal diode laser treatment and Milligan-Morgan hemorrhoidectomy. Menoufia Med. J 2019; 32: 560-5. 